\title{
Lean manufacturing and Toyota Production System terminology applied to the procurement of vascular stents in interventional radiology
}

\author{
Maximilian de Bucourt • Reinhard Busse • \\ Felix Güttler • Christian Wintzer • Federico Collettini • \\ Christian Kloeters • Bernd Hamm • Ulf K. Teichgräber
}

Received: 11 October 2010 /Revised: 20 November 2010/Accepted: 7 April 2011 /Published online: 21 April 2011

(C) European Society of Radiology 2011

\begin{abstract}
Objectives To apply the economic terminology of lean manufacturing and the Toyota Production System to the procurement of vascular stents in interventional radiology. Methods The economic- and process-driven terminology of lean manufacturing and the Toyota Production System is first presented, including information and product flow as well as value stream mapping (VSM), and then applied to an interdisciplinary setting of physicians, nurses and technicians from different medical departments to identify wastes in the process of endovascular stent procurement in interventional radiology.

Results Using the so-called seven wastes approach of the Toyota Production System (waste of overproducing, waiting, transport, processing, inventory, motion and waste of defects and spoilage) as well as further waste characteristics (gross waste, process and method waste, and micro waste), wastes in the process of endovascular stent procurement in interventional radiology were identified and eliminated to create an overall smoother process from the procurement as well as from the medical perspective.

Conclusion Economic terminology of lean manufacturing and the Toyota Production System, especially VSM, can be used to visualise and better understand processes in the procurement of vascular stents in interventional radiology from an economic point of view.
\end{abstract}

M. de Bucourt $(\bowtie) \cdot$ R. Busse $\cdot$ F. Güttler $\cdot$ C. Wintzer $\cdot$

F. Collettini $\cdot$ C. Kloeters $\cdot$ B. Hamm $\cdot$ U. K. Teichgräber

Charité - University Medicine Berlin,

Charité Platz 1,

10117 Berlin, Germany

e-mail: mdb@charite.de
Keywords Lean management - Toyota Production System · Procurement $\cdot$ Waste $\cdot$ Value stream mapping

\section{Introduction}

Medical administrative departments often criticise the lack of ability of medical professionals to comply with given budget constraints and to efficiently organise their clinical workflow.

On the one hand, one may rightfully argue that the medical perspective, especially in terms of patients and their treatment, by definition should not and must not be a solely economic one. On the other hand, the "noncompliance of medical professionals" may be partially due to a lack of knowledge about how to implement economic concepts to reduce inefficiencies in workflow.

It can be generally agreed that not only budget constraints but also mere ratio implies organising every workflow and every process efficiently. In New Institutional Economics terminology, "economy" itself can be defined as nothing more than the efficient reallocation of scarce goods. Also, the debate on "prioritisation" in health care environments (i.e. making best use of time and resources) in Germany, initiated by the president of the Federal Physicians Chamber (Bundesärztekammer; the central organisation in the system of medical self-administration in Germany), Prof. Dr. med. Jörg-Dietrich Hoppe, is just one recent example that highlights the evident scarcity of resources and the discussion of their efficient allocation. This discussion reveals an ideological component as well.

This paper intends to introduce medical professionals to basic economic terminology and concepts of lean manufacturing and the Toyota Production System, including 
value stream mapping (VSM), and then to demonstrate how this economic point of view can be used to visualise, better understand and efficiently organise processes in the procurement of vascular stents in interventional radiology.

\section{Materials and methods}

General information and definitions of lean manufacturing and the Toyota production system

The Toyota Production System (TPS), formerly also known as "just in time production" (JIT), is an integrated sociotechnical system that can be defined as the major precursor to the more general concept "lean manufacturing".

Lean manufacturing is a production philosophy which considers any resource expenditure for any goal other than the creation of value for the end customer to be wasteful and thus a target for elimination. It is often linked to the "six sigma" quality strategy because of the methodology's emphasis on the reduction of process variation (which six sigma intends to control up to the sixth standard deviation of possible failure).

There are two general - and to some extent intersecting approaches to appreciating the lean concept: waste and smoothness. Lean can be considered as the set of TPS (and other economic) "tools" that assist in the identification and steady elimination of waste (muda) by improving quality while reducing production time and cost. These tools include continuous process improvement (kaizen), mistake-proofing (poka-yoke) as well as a question-asking method most commonly known as "the 5 whys," used to explore the cause-effect relationships underlying particular problems by avoiding assumptions with the goal of ultimately determining the root cause.

Smoothness can be appreciated in many industrialmanufacturing companies that have implemented TPS concepts, including of course Toyota itself. Thereby the focus is upon implementing an efficient "flow" of work throughout the complete system and not upon "waste reduction" per se. Techniques to improve smoothness include production levelling (heijunka) and visual scheduling (e.g. heijunka box) as well as "pull" production (by means of kanban). A glossary of the terminology commonly applied in TPS and lean manufacturing is provided in Table 1.

Inventory calculation and push and pull characteristics

Inventory and calculation Physically counting and validating inventory is generally very time-consuming and hence expensive. Sometimes it can be performed with computer assistance, e.g. by means of radio-frequency identification (RFID) [1-4], which generally facilitates the process. Depending on the industry, the business and the specific inventory, inventory calculation is usually conducted at more or less set points in time during a year. Therefore it has to be taken into account that in the intervals in-between, the inventory might be much higher or lower. Once an average inventory is estimated, it should be divided by the daily production rate (or use rate) for that item in order to estimate the daily on-hand inventory. This calculation can be interpreted as a modification of "Little's law", a mathematical theory of queues: the long-term average number of an item in a stable system $L$ equals the longterm average arrival rate, $\lambda$, multiplied by the long-term average time of an item spent in the system $W(L=W \lambda)$.

Push system Push systems refer to conventional inventory control and scheduling. In push systems, a schedule goes out to all of the various processes and each process attempts to work to this schedule. If a particular process experiences difficulties in keeping the pace, the processes upstream and downstream are usually unaware of it and keep working to the original schedule. Variances between scheduled activity and actual execution necessitate large inventories or multiple inventory stocks throughout the process.

Pull system In pull systems, a relatively small inventory of every item necessary is held between processes in so-called kanban stock points (sometimes also referred to as "supermarkets"). A downstream process simply takes what it needs, the shortage is visualized, and the upstream process replaces it. Kanban systems are generally considered advantageous when a process produces multiple parts in small amounts.

\section{Process mapping}

Process mapping is one of the oldest but a very valuable technique for streamlining workflow. Process mapping in general refers to activities involved in defining exactly what a business entity does, who is responsible, to what standard a process should be completed and how the success of a business process can be assessed. After successful process mapping, there should be no uncertainty regarding the process. A rather modern approach focusing on the value stream of procedures is known as value stream mapping (VSM).

\section{Value stream mapping}

Value stream mapping (VSM) is a process for planning and linking lean initiatives through systematic data acquisition and analysis that often gives additional insights. Figure 1 depicts a typical VSM with information flow (red line) and material flow (blue line). The various icons have specific meanings; knowledge of these symbols as well as knowledge of the TPS are necessary to interpret a VSM and to 
Table 1 Glossary of the main terminology applied in the Toyota Production System and lean manufacturing
Jidoka (自働化)

Heijunka (平準化)

Kaizen (改善)

Kaizen event

Kanban (看板)

Lean

Muda (無駄)

Poka-yoke (ポカヨケ)
Using intelligent automation-sometimes also referred to as "autonomation" or automation with a human touch-to promote flow. This term describes a quality control supervisory process that prevents the production of continuous defective products by detecting production abnormality, stopping it, immediately fixing or correcting it and investigating the root cause in order to prevent it from reoccurring.

The Heijunka box is a visual production smoothing or production levelling mechanism to produce intermediate goods at a constant rate, thus allowing further processing to be carried out at a constant and predictable rate that distributes the finishing schedule into small time increments. The heijunka box is generally a wall schedule that is divided into a grid of boxes, each one representing a specific unit of time; lines are drawn down the schedule to break it into columns of days or weeks.

The term connotes "change for the better" or "improvement". The Japanese character "kai" stands for "take apart," and "zen" connotes "make good." An adequate English translation is "continuous process improvement". Kaizen is a quality strategy that is aimed at eliminating waste by eliminating any activities that add cost without adding value.

A kaizen event or "kaizen blitz" is a team event dedicated to quickly implementing a lean manufacturing method in a particular area in a very short time period.

"Kan" means visual, and "ban" means card or board; the term implies an inventory control method that historically used cards to signal the need for an item. However, other devices such as plastic markers (Kanban squares) or balls (e.g. golf balls) or an empty transport trolley can also be used to trigger the movement, production or supply of a unit in a factory. Kanban is a textbook example of a demand-driven (economic production) pull system.

Short form for lean manufacturing - minimising waste and maximising flow. In the literature the term is translated as "waste" but more precisely implies any human activity that absorbs resources without creating value. The Japanese antonym of "muda" can be translated as "usefulness", which may assist in more adequately identifying the meaning of the Japanese term: anything in a work process that adds cost or time without adding value can be regarded as "muda."

Poka-yoke means "mistake-proofing"-avoiding (yokeru) inadvertent errors (poka) is a behaviour-shaping constraint, or a method of preventing errors by putting limits on how an operation can be performed in order to force the correct completion of the operation. The original term was Baka-yoke, but as this more precisely connotes "fool-proofing" (or "idiot proofing") the name was modified to the more companionable Poka-yoke. use it well. Like geographic maps, value stream maps come in various forms and levels of detail, depending on the purpose and the processes analysed.

According to the standards of Japanese engineer Shigeo Shingo - one of the leading experts on manufacturing practices and the TPS — value-adding steps should be drawn across the centre of the map and non-value-adding steps should be depicted in vertical lines, at right angles to the value stream. Shigeo Shingo calls the value stream the "process" and the nonvalue streams the "operations". Each vertical line represents the story of a person or workstation while the horizontal line represents the story of the product in creation. Thus, processes and operations are easily separated.
VSM is commonly used in lean environments to identify opportunities for improvement in lead-times. Although VSM is often associated with manufacturing, it is also applied in logistics, supply chains, and service-related industries including health care, software and product development [5-7].

A convenient method of gaining economic insights into one's own institution is to classify each step along a value stream according to the following three characteristics:

- $\quad$ Non-value adding (NVA)

- Necessary but non-value adding (NNVA)

- Value adding (VA) 
Fig. 1 Example of value stream mapping (VSM) from the manufacturing industry presenting information flow (red) and material flow (blue)

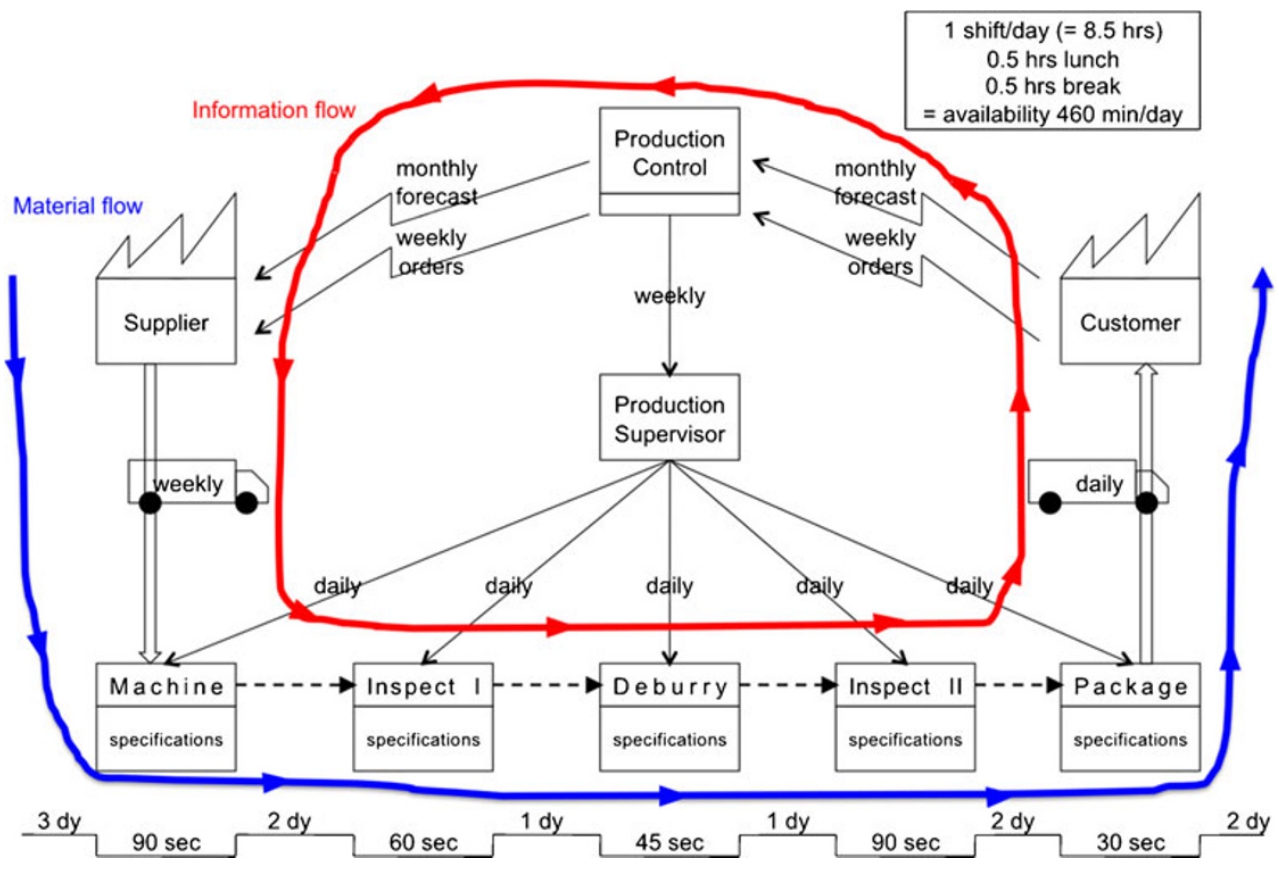

Non-value-adding activities are pure muda. They are unnecessary actions and hence should be eliminated completely. Examples are waiting times, stacking intermediate products or double handling.

Necessary but non-value-adding activities may be wasteful but are necessary or mandatory under current (e.g. operating) procedures. Examples include walking to pick up parts and unpacking deliveries. In order to eliminate these types of operations, it is often necessary to implement major changes in the clinical setup, e.g. operation system and architecture.

Value-adding activities involve the useful and further conversion or processing of raw materials to semi-finished and ultimately to finished products.

\section{Results}

In an interdisciplinary approach including referrers (physicians, nurses and other staff on referring wards, e.g. vascular surgery), conductors (interventional radiologists, nurses, technicians and staff of the angio suite) and specialists of the hospital's controlling department, the process of ordering vascular stents and treating respective patients was analysed in order to eliminate inefficiencies.

As the ultimate lean target is the total elimination of waste (waste, or muda, is anything that adds cost or time without adding value), the process was analysed by pursuing a waste-driven approach, i.e. identifying waste in order to achieve a smoother, more VA-centred process. "Wastes" were classified according to the "seven wastes" first identified by Toyota's chief engineer, Taiichi Ohno.
The seven wastes of the TPS are listed below and described from both the procurement and medical perspective:

1. Waste of overproducing

2. Waste of waiting

3. Waste of transport

4. Waste of processing

5. Waste of inventory

6. Waste of motion

7. Waste of defects and spoilage

1. Waste of overproducing: producing components that are not intended for immediate use or sale.

- From the procurement perspective:

- Not applicable since stents are not produced but ordered. Concerning adequate stent orders, this becomes a possible waste of inventory (see below).

- From the medical perspective:

- Given a justified indication for stent implementation from a medical point of view, this type of waste was not considered applicable.

2. Waste of waiting: idle time between operations or during an operation due to missing material, an unbalanced line, scheduling mistakes, etc.

- From the procurement perspective:

- Waiting for orders of stents and other medical equipment coming in at the controlling department from the interventional radiology department. If information flow is interrupted, this 
may delay the process of ordering and, in the case of missing inventory, this may lead to a delay in medical treatment. Switching from paper/fax orders to electronic/digital ordering to achieve a valid and trackable information flow was indicated. This should also prevent "double orders" and lost faxes/papers. With the new digital ordering process, the former paper/ fax option was identified as NVA waste.

- From the medical perspective:

- Waiting for patients/necessary data: patients are transported from the wards to the angio suite by an external transportation service. The transportation system is requested electronically for a given time, but it is known that, especially between 1200 and 1400, the service is congested, with possible delays of up to $1 \mathrm{~h}$. As idle time is very cost-intensive, a supervisory room was created within the angio suite to increase independence. Thus, patients can be transported earlier via the transportation service and wait if applicable in the supervisory room until the intervention can take place. This reduces interruptions and increases smoothness. The former delay possibility was considered NVA waste.

- Waiting for staff, equipment and free angio suites: This includes waiting for staff who are otherwise busy (e.g. on ward, still in another angio suite) or sick (especially in combination with possible bottlenecks during vacation periods); waiting for special equipment (e.g. equipment currently being used in another angio suite); or waiting for a free angio suite because of delays in previous interventions or mismanagement. To prevent these situations, one interventional planner/manager was selected to organise an efficient infrastructure for all interventional subspecialties in the hospital's angio suites. Before, each subspecialty (angiography/ internal medicine, interventional radiology, neuroradiology) independently organised their own staffing and equipment. The new organisational structure also facilitates helping out at other subspecialties if necessary and includes an immediate feedback mechanism with all subspecialties for critical events in the past and possible bottlenecks in the future. Any type of waiting was considered NVA waste.

3. Waste of transport: moving material more than necessary. This is often caused by poor layout.

- From the procurement perspective:
- After ordering stents and medical equipment, external suppliers of medical material organise transportation to the hospital. This transport is necessary and-given the specialisation of producing stents and medical equipmentcannot be substantially abbreviated in terms of logistics and geography.

- From the medical perspective:

- Inside the hospital, stents first enter the incoming goods department (first visual inspection), then enter central storage (second intensive inspection), then enter withinhospital package/delivery and finally reach the angio suite's inventory where they are again finally checked before implementation. Given that stents can be considered specialised - almost custom fit-medical items, a direct delivery to the point of usage was considered smoother. All previous inspections were considered NVA waste and could be eliminated. The architectural position of the angio suites inside the hospital was considered given. The design of the inventory rooms inside the angio suites and the arrangement of the drawers were considered useful and ergonomic.

4. Waste of processing: doing more to the product than necessary. This is the single most difficult type of waste to identify and eliminate. Reducing such waste often involves eliminating unnecessary work elements [including inspection through implementation of automation in such a way to promote flow (Jidoka)].

- From the procurement perspective:

- This type of waste was considered not applicable.

- From the medical perspective:

- The goal was to avoid unnecessary, partial and partially redundant interventions caused by a lack of knowledge, competence or (stent) material. A certified interdisciplinary conference was created with specialists of interventional radiology, vascular surgeons, angiographers from internal medicine and referring physicians in order to discuss patients and their respective needs all together in advance. Any subsequent intervention due to a previously, only partially, conducted medical intervention (either due to partial knowledge, limited material or limited expertise) was considered NVA waste.

5. Waste of inventory: excess stock in the form of raw materials, work-in-progress, and finished goods. 
- From the procurement perspective:

- Previously, specialised - almost custom fitmedical materials such as stents were centrally ordered, centrally received, centrally stored and finally delivered to the angio suite. The central storage and the unnecessary inspections were eliminated (see waste of transport) by directly requiring the stent producer to transport the item to the angio suite. The central inventory was considered NVA. The order responsibility remained with the central purchasing of the hospital for overall bargaining power.

- From the medical perspective:

- Previously, the whole procurement system was rather push-driven. Average estimates of quantities were used for stent orders and medical equipment, although a feedback mechanism already existed. Still, the risk of medical items reaching expiry dates remained, which for stents especially is very cost-intensive. At the angio suite inventory, a kanban system was implemented. The angio suite's inventory drawers were labelled with visual icons and became "local supermarkets" that now trigger the ordering of new items when almost empty, thus changing the system to a more demanddriven pull system. At the given quantities, the push-driven inventory approach was considered NVA waste, especially because large inventories of specialised medical materials are very cost-intensive.

6. Waste of motion: any motion that is not necessary to the successful completion of an operation. Obvious forms of motion waste include back-and-forth movement in the workstation and searching for parts or tools. A more subtle form of motion waste involves any change in a worker's centre of gravity. Thus, any time a worker stretches, bends or twists, it is a waste of motion.

- From the procurement perspective:

- Waste of motion has been identified as subsets of previously described waste forms (see waste of inventory, waste of process, waste of transport and waste of waiting).

- From the medical perspective:x

- All interventions require advance preparation of the patient from the nurse, as well as advance preparation of multiple medical items and tools from a rather voluminous inventory (i.e. a large number of different items held within the inventory rather than a large inventory of a few different items only). In order to reduce the probability of possibly forgotten items - which then would reduce process smoothness as they would have to be prepared or organised during an interventionstandard operating procedures (SOP) for all major standard interventions were formulated, including desired image documentation of crucial steps, patient preparation, necessary laboratory values and necessary experience of the physician (or respective sufficient medical supervision expertise). Also all inventory drawers were affixed with pictures of every item they carry, so that each item can also be found quickly by a visual scan. Any motion of patients, physicians, nurses and technicians that was not necessary for the completion of an operation or negatively affected process smoothness was considered NVA waste.

7. Waste of defects and spoilage: producing defective goods or mishandling materials. This includes the waste inherent in having to rework parts not made correctly the first time. It also includes productivity losses associated with disrupting the continuity of a process to deal with defects or reworking. Defects are regarded as bottom-line waste as these are direct costs. In TPS philosophy, defects should be regarded as an opportunity to improve rather than a trade-off for what is ultimately poor management. Thus, defects are opportunities for immediate kaizen activities.

- From the procurement perspective:

- Stents are produced by a relatively small number of medical companies. While it is generally possible to change to a different producer in the case of frequent or increasing defects (or bottlenecks in the timely procurement), it may not always be possible due to specialised characteristics of certain stents in their repertoire. In general, spoiled products from the procurement site were considered negligible.

- From the medical perspective:

- In order to reduce waste of defects and spoilage from the medical perspective, adequate experience of the physician (including mastering possible complications or supervision by a more experienced physician), the nurse and the technician were considered indicative factors for providing adequate preparation of patients, medical items and tools and for allowing for an overall smooth process until final stent implantation without damage to patients, employees 
Table 2 Levels of waste and possible solutions applied to the procurement process of vascular stents in the interventional radiology department

\begin{tabular}{|c|c|c|c|c|c|}
\hline \multicolumn{2}{|l|}{ Level 1} & \multicolumn{2}{|l|}{ Level 2} & \multicolumn{2}{|l|}{ Level 3} \\
\hline Gross waste & Possible solution & $\begin{array}{l}\text { Process and } \\
\text { method waste }\end{array}$ & Possible solution & Micro waste & Possible solution \\
\hline In general & Institutional level & In general & Process level & In general & Personal level \\
\hline $\begin{array}{l}\text { Work-in- } \\
\text { progress }\end{array}$ & $\begin{array}{l}\text { Scheduling } \\
\text { improvement }\end{array}$ & Long changeover & $\begin{array}{l}\text { Preparation in } \\
\text { advance }\end{array}$ & $\begin{array}{l}\text { Excess walking, looking for stock, } \\
\text { speed and feed, bending and } \\
\text { reaching, double handling }\end{array}$ & $\begin{array}{l}\text { Improving ergonomic } \\
\text { behaviour and } \\
\text { thinking in advance }\end{array}$ \\
\hline $\begin{array}{l}\text { Poor plant } \\
\text { layout }\end{array}$ & $\begin{array}{l}\text { Architectural } \\
\text { optimisation }\end{array}$ & $\begin{array}{l}\text { Late } \\
\text { maintenance }\end{array}$ & $\begin{array}{l}\text { Request in } \\
\text { advance }\end{array}$ & Paperwork & $\begin{array}{l}\text { Reduce and delegate } \\
\text { as much as possible }\end{array}$ \\
\hline $\begin{array}{l}\text { Rejected, } \\
\text { returned and } \\
\text { damaged } \\
\text { products }\end{array}$ & $\begin{array}{l}\text { Prevention and } \\
\text { advance } \\
\text { identification }\end{array}$ & $\begin{array}{l}\text { Temporary } \\
\text { storage }\end{array}$ & $\begin{array}{l}\text { As little as } \\
\text { possible }\end{array}$ & & \\
\hline $\begin{array}{l}\text { Dirty } \\
\text { equipment }\end{array}$ & $\begin{array}{l}\text { Meet hygiene } \\
\text { standards }\end{array}$ & $\begin{array}{l}\text { Equipment } \\
\text { problems }\end{array}$ & Check in advance & & \\
\hline Rework & $\begin{array}{l}\text { Attain best } \\
\text { medical practice }\end{array}$ & Unsafe method & Reject in advance & & \\
\hline $\begin{array}{l}\text { Container and } \\
\text { batch size }\end{array}$ & $\begin{array}{l}\text { Architectural/ } \\
\text { conceptual } \\
\text { efficiency }\end{array}$ & $\begin{array}{l}\text { Poor workplace } \\
\text { design for } \\
\text { specific } \\
\text { processes }\end{array}$ & $\begin{array}{l}\text { Improve set-up in } \\
\text { advance as much } \\
\text { as possible }\end{array}$ & & \\
\hline $\begin{array}{l}\text { Material not } \\
\text { delivered to } \\
\text { point of use }\end{array}$ & $\begin{array}{l}\text { Clear and } \\
\text { binding orders, } \\
\text { e.g. } \\
\text { visualisation }\end{array}$ & No SOP & SOP creation & & \\
\hline
\end{tabular}

and materials. Selecting a responsible interventional planner/manager (see also waste of waiting) was considered helpful to account for sufficient experience, expertise and staff for each subspecialty at all times. Any preventable defect or spoilage of stents and other medical items affecting patients and employees was considered NVA waste.

To further characterise wastes identified by the seven wastes strategy, the classification presented in Table 2 was used to differentiate waste into gross waste (level 1), process and method waste (level 2) and micro waste (level 3).

\section{Discussion}

Economic tools such as six sigma [8], lean manufacturing and the TPS [9-11] have been increasingly applied in health care over the last couple of years. Organisational structures targeted include ambulatory and practice settings [12, 13], clinical departments [14], hospitals and medical centres [15-17], health care chains [18] and national health services [19].

In general it can become challenging to adopt economic tools adequately in health care environments because the relationship between supplier and customer is not as straightforward as in usual business industries. One major reason for the more complicated situation in health care systems is the triangular flow of goods and services among patient, physician and insurer: While patients receive a service from the physician (or the medical unit), they reimburse the insurer via the insuring fee. While physicians (or the medical unit) receive a reimbursement from the insurer, they treat the patient, and while the insurer receives payments from the patient, the reimbursement is forwarded to the physician. Thus, there is always an indirect flow of goods and services, rendering health care environments and all of their participants very susceptible to known quality control as well as economic dilemmas (e.g. principal agent, ex post and ex ante moral hazard, adverse selection, information asymmetry). The aforementioned triangular relationship in health care is also one of the major reasons why the "patient" may not (or cannot) be reduced to an ordinary "customer". After all, they may not only be customers, and-depending on the point of view-they may not be the only "customers" in the system, as there are also insurers and physicians (and the governing state).

Nonetheless, applying economic tools from a medical point of view is worth the effort, especially as health care leaders search for viable options to cut costs, increase efficiencies and improve products and services [20]. One major reason for rising health care costs is medical errors, and Printezis and Gopalakrishnan point out that most of 
these result from faulty systems and processes [21]. Health care has advanced in the technology and understanding of disease, but its business and management systems have barely changed since the 1950s [22]. Steven Spear put it provocatively in a Harvard Business Review in 2005: "Today, you are about as safe in a U.S. hospital as you would be parachuting off a bridge or a building," concluding that economic tools such as TPS can indeed be used to remove ambiguity in output, responsibilities, connections and methods of work processes [23]. Rather than focusing on cutting personnel and assets, the lean idea seeks to improve patient satisfaction through improved actions and processes [24].

While it is possible in principle to use industrial engineering-based tools in health care organisations to improve process outcomes, reduce risk, improve patient safety, improve through-put, and reduce costs, many health care organisations lack experience in applying them and therefore do not understand how and when to use them correctly [25].

In this context, the economic terminology of lean manufacturing and the TPS, especially VSM, can be used to visualise and better understand processes in the procurement of vascular stents in interventional radiology from an economic point of view.

Information gained from process maps and value stream mapping

Process maps are an ideal technique for Kaizen events with limited training time because they are generally simple and intuitive. All work or purposeful activity can be interpreted as a process, defined as a prescribed sequence of events leading to a final product. Sometimes the process may not be orderly and the prescribed sequence may be vague. Depending on the process, time estimations may further be unreliable and should hence be even more subject to proof. This is especially true in hospital environments. Process maps give an overview, especially about the order in which activities are performed. Conducting process maps certainly assists employees in understanding their own involvement in the process and especially their interrelating interfaces with others. Analysing the process may lead to a change in the sequences performed. A main limitation of process mapping is that it does not represent information flows. For mapping information, VSM is also by definition more appropriate.

What kind of waste reduction is realistic

Waste reduction is the main manufacturing paradigm in lean manufacturing. There is a difference between doing something lean and being lean. In 1990, James Womack and Daniel Roos coined the term "lean" in their book The Machine that Changed the World. Lean refers to a manufacturing paradigm based on the fundamental goal of the TPS: continuously minimising waste in order to maximise flow. To become lean requires changing the mind-set. Many manufacturing organisations have recognised the importance of lean management. However, many organisations are doing lean without necessarily becoming lean. Typically, such organisations sporadically implement improvements without linking their efforts to an overarching strategy. The TPS is more than applying individual methods and tools such as VSM. The purpose of lean is to use the appropriate tools in such a way that everyone connected within the value stream can work together to improve overall flow and eliminate overall waste. Not surprisingly, Fidsa found that a holistic problem solving design is usually less expensive and less wasteful in the long run because it avoids solving one problem within a complex system at the cost of creating other problems within that very system [26].

\section{References}

1. Ting SL, Kwok SK, Tsang AH, Lee WB (2009) Critical elements and lessons learnt from the implementation of an RFID-enabled healthcare management system in a medical organization. J Med Syst. doi:10.1007/s10916-009-9403-5

2. Shim H, Uh Y, Lee SH, Yoon YR (2010) A new specimen management system using RFID technology. J Med Syst. doi:10.1007/s10916-009-9417-z

3. Chien HY, Yang CC, Wu TC, Lee CF (2009) Two RFID-based solutions to enhance inpatient medication safety. J Med Syst. doi:10.1007/s10916-009-9373-7

4. Kumar S, Livermont G, McKewan G (2010) Stage implementation of RFID in hospitals. Technol Health Care 18(1):31-46

5. Rutledge J, Xu M, Simpson J (2010) Application of the Toyota Production System improves core laboratory operations. Am J Clin Pathol 133(1):24-31

6. Serrano L, Hegge P, Sato B, Richmond B, Stahnke L (2010) Using LEAN principles to improve quality, patient safety, and workflow in histology and anatomic pathology. Adv Anat Pathol 17(3):215-221

7. Melanson SE, Goonan EM, Lobo MM, Baum JM, Paredes JD, Santos KS et al (2009) Applying Lean/Toyota production system principles to improve phlebotomy patient satisfaction and workflow. Am J Clin Pathol 132(6):914-919

8. Fischman D (2010) Applying lean six sigma methodologies to improve efficiency, timeliness of care, and quality of care in an internal medicine residency clinic. Qual Manag Health Care 19 (3):201-210

9. Rangachari P (2010) Knowledge sharing and organizational learning in the context of hospital infection prevention. Qual Manag Health Care 19(1):34-46

10. Burkitt KH, Mor MK, Jain R, Kruszewski MS, McCray EE, Moreland ME et al (2009) Toyota production system quality improvement initiative improves perioperative antibiotic therapy. Am J Manag Care 15(9):633-642 
11. Siebert JR (2009) Increasing the efficiency of autopsy reporting. Arch Pathol Lab Med 133(12):1932-1937

12. Rizzo AA, Dommert HJ (2009) Value stream mapping: a case study of one practice's experience. Del Med J 81(5):187-188

13. Casey JT, Brinton TS, Gonzalez CM (2009) Utilization of lean management principles in the ambulatory clinic setting. Nat Clin Pract Urol 6(3):146-153

14. Ng D, Vail G, Thomas S, Schmidt N (2010) Applying the Lean principles of the Toyota Production System to reduce wait times in the emergency department. CJEM 12(1):50-57

15. Furman C, Caplan R (2007) Applying the Toyota Production System: using a patient safety alert system to reduce error. Jt Comm J Qual Patient Saf 33(7):376-386

16. Stapleton FB, Hendricks J, Hagan P, DelBeccaro M (2009) Modifying the Toyota Production System for continuous performance improvement in an academic children's hospital. Pediatr Clin N Am 56(4):799-813

17. Young JQ, Wachter RM (2009) Applying Toyota Production System principles to a psychiatric hospital: making transfers safer and more timely. Jt Comm J Qual Patient Saf 35(9):439-448

18. Brown T, Duthe R (2009) Getting 'Lean': hardwiring process excellence into Northeast Health. J Healthc Inf Manag 23(1):3438
19. Grove AL, Meredith JO, Macintyre M, Angelis J, Neailey K (2010) Lean implementation in primary care health visiting services in National Health Service UK. Qual Saf Health Care 19(5):e43

20. Nelson-Peterson DL, Leppa CJ (2007) Creating an environment for caring using lean principles of the Virginia Mason Production System. J Nurs Adm 37(6):287-294

21. Printezis A, Gopalakrishnan M (2007) Current pulse: can a production system reduce medical errors in health care? Qual Manag Health Care 16(3):226-238

22. Kaplan GS, Patterson SH (2008) Seeking perfection in healthcare. A case study in adopting Toyota Production System methods. Healthc Exec 23(3):16-18, 20-21

23. Spear SJ (2005) Fixing health care from the inside, today. Harv Bus Rev 83(9):78-91, 158.

24. Weinstock D (2008) Lean healthcare. J Med Pract Manage 23 (6):339-341

25. Rath F (2008) Tools for developing a quality management program: proactive tools (process mapping, value stream mapping, fault tree analysis, and failure mode and effects analysis). Int J Radiat Oncol Biol Phys 71(1 Suppl):S187-S190

26. Fidsa GZ (2009) Designing the future of healthcare. Stud Health Technol Inform 149:49-57 